Therapeutics

\section{Acupuncture is not as effective as infertility treatment in women with PCOS}

10.1136/ebmed-2017-110828

\begin{abstract}
Liangzhi $\mathrm{Xu}{ }^{1,2,3}$ Xiaoyong Qiao ${ }^{1,2,3}$
${ }^{1}$ Department of Obstetrics and Gynecology, West China Second University Hospital, Sichuan University, Chengdu, China, ${ }^{2}$ The Joint Laboratory for Reproductive Medicine of Sichuan University, The Chinese University of Hong Kong, Chengudu, China, ${ }^{3}$ Key Laboratory of Birth Defects and Related Diseases of Women and Children, Sichuan University, Ministry of Education, Chengudu, China
\end{abstract}

Correspondence to: Dr Liangzhi Xu, Department of Obstetrics and Gynecology, West China Second University Hospital, Sichuan University, Chengdu, Sichuan 610041, China; liangzxu@126.com

Commentary on: Wu XK, Stener-Victorin E, Kuang HY, et al. Effect of acupuncture and clomiphene in Chinese women with polycystic ovary syndrome: a randomised clinical trial. JAMA 2017;317:2502-14.

\section{Context}

Ovulatory dysfunction is considered to be one of the major characteristics of polycystic ovary syndrome (PCOS), which affects 5\%-10\% of women of reproductive age and leads to $70 \%-80 \%$ of anovulatory infertility. Many ovulation induction treatments, including clomiphene citrate, letrozole, exogenous gonadotropin and laparoscopic ovarian drilling, have limited effectiveness, safety and negative side effects. Acupuncture has been used in eastern Asian countries for thousands of years, and the use of acupuncture in reproductive endocrinology and infertility is becoming popular in research and clinical practice. Several clinical and animal experimental studies indicate that acupuncture may improve ovulation frequency by improving endocrine profile and normalising insulin sensitivity. ${ }^{12}$ However, evidence is of very low quality. Many studies have limitations, including failure to report important clinical outcomes, poor reporting of study methods, non-randomised controlled studies, small sample size and insufficient information on allocation concealment in randomised clinical trials; even the latest systematic review and meta-analysis still came to the conclusion that there is currently insufficient evidence to support the use of acupuncture for treatment of ovulation disorders in women with PCOS. ${ }^{34}$

\section{Methods}

This study carried out by $\mathrm{Wu}$ and colleagues assessed whether active acupuncture, either alone or combined with clomiphene, increases the likelihood of live births among women with PCOS. This was a randomised, multicentre, clinical trial undertaken in 27 hospitals.
Double-blind (clomiphene vs placebo) and single-blind (active vs control acupuncture) factorial trials were conducted in PCOS. Live birth was the primary outcome, and adverse events were evaluated as the secondary outcomes.

\section{Findings}

Live births occurred in $29.4 \%$ of women treated with the active acupuncture plus clomiphene, $28.0 \%$ of women in the control acupuncture plus clomiphene group, $13.9 \%$ in the active acupuncture plus placebo group and $16.8 \%$ in the control acupuncture plus placebo group. There was no significant interaction between active acupuncture and clomiphene, although the live birth rate was significantly higher in the women treated with clomiphene than with placebo. Diarrhoea and bruising were more common in patients receiving active acupuncture than control acupuncture. $^{5}$

\section{Commentary}

These findings indicate that acupuncture, alone or with clomiphene, was not as effective as an infertility treatment in women with PCOS. In this research, circulating levels of progesterone, total testosterone, oestradiol and sex hormone-binding globulin were not significantly different between women receiving active versus control acupuncture. The results suggest that acupuncture may not improve serum indexes, although some animal experiment and clinical contrast studies suggest it may change the PCOS serum indexes, the inconsistency may be due to small simple size or confounding factors. Previous study suggested acupuncture can improve the insulin sensitivity. In this study, the author did not evaluate the changes in insulin sensitivity. The frequency of serious adverse events was very low and did not differ significantly among the groups. In the aspect of the adverse event, clomiphene was more frequently associated with back pain, while acupuncture may reduce the occurrence. Clomiphene is a first-line treatment drug in ovulation induction, and was used as positive control in this study. Many studies suggested that letrozole has the same and even better effect in ovulation induction for PCOS. ${ }^{6}$

\section{Implications for practice}

Whether acupuncture can play a synergistic role with letrozole requires further study because of different ovulation mechanisms, although clomiphene has no synergistic effect with acupuncture.

Although important clinical outcomes were explored in this study, many details still need an explanation, for example, the acupuncture points are different between active acupuncture and control groups with resultant deficiency in blinding, and the average dosage and frequency of clomiphene in ovulation induction have not been statistically analysed. In summary, this study by Wu et al prompts us to reconsider the role of acupuncture in the treatment of ovulation disorders in women with PCOS.

Competing interests None declared.

Provenance and peer review Commissioned; internally peer reviewed.

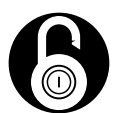
OPEN ACCESS 
Open Access This is an Open Access article distributed in accordance with the Creative Commons Attribution Non Commercial (CC BY-NC 4.0) license, which permits others to distribute, remix, adapt, build upon this work non-commercially, and license their derivative works on different terms, provided the original work is properly cited and the use is non-commercial. See: http://creativecommons.org/licenses/ by-nc/4.0/

- Article author(s) (or their employer(s) unless otherwise stated in the text of the article) 2017. All rights reserved. No commercial use is permitted unless otherwise expressly granted.

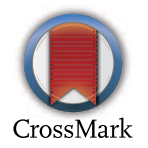

\section{References}

1. Johansson J, Stener-Victorin E. Polycystic ovary syndrome: effect and mechanisms of acupuncture for ovulation induction. Evid Based Complement Alternat Med 2013;2013:1-16.

2. Johansson J, Redman L, Veldhuis PP, et al. Acupuncture for ovulation induction in polycystic ovary syndrome: a randomized controlled trial. Am J Physiol Endocrinol Metab 2013;304:E934-E943.

3. Jo J, Lee YJ, Lee H. Acupuncture for polycystic ovarian syndrome: a systematic review and meta-analysis. Medicine 2017;96:e7066.

4. Wu XK, Stener-Victorin E, Kuang HY, et al. Effect of acupuncture and clomiphene in Chinese women with polycystic ovary syndrome: a randomized clinical trial. JAMA 2017;317:2502-14.

5. Lim CE, Ng RW, Xu K, et al. Acupuncture for polycystic ovarian syndrome. Cochrane Database Syst Rev 2016:CD007689.

6. Misso ML, Wong JL, Teede HJ, et al. Aromatase inhibitors for PCOS: a systematic review and meta-analysis. Hum Reprod Update 2012;18:301-12. 